\title{
Upcoming expert opinions on adult coronary surgery
}

Leora B. Balsam, MD, ${ }^{a}$ and Mario Gaudino, $\mathrm{MD}^{\mathrm{b}}$

This year, readers will have access to a number of highimpact Invited Expert Opinion articles on important topics in coronary surgery ranging from the continued debate surrounding multiple arterial grating (MAG) to the optimal use of graft flow measurement. In this era of rapidly evolving evidence across the field of coronary artery bypass grafting (CABG), experts will guide clinicians on everyday management and intraoperative decision making with the goal of improving patient care through an evidence-based approach.

MAG has seen a recent renaissance in cardiac surgery. Recently published randomized evidence has demonstrated superior long-term outcomes associated with MAG. ${ }^{1,2} \mathrm{Few}$ have contributed more to the evolution of MAG than Stephen Fremes from the Sunnybrook Health Sciences Centre in Ontario, Canada. In the JTCVS Open, Fremes and colleagues $^{3}$ expertly summarize the evidence supporting the use of MAG, particularly in patients with a long life expectancy.

Despite this wave of promising evidence, the use of MAG remains suboptimal. ${ }^{4}$ Gaudino, Kurlansky, and Fremes ${ }^{5}$ will discuss ways in which health care systems may disincentivize surgeons' use of MAG by focusing on shortterm rather than long-term patient outcomes. In another article, Vallely and colleagues ${ }^{6}$ will directly address 3 major concerns related to MAG; namely, the lack of supportive randomized evidence given the neutral results of the Arterial Revascularization Trial, potential for increased morbidity and mortality, and the perceived increased technical complexity. Furthermore, Kurlansky ${ }^{7}$ will maintain that the answer to "should I use MAG?" is a resounding yes as he explains why further research is needed.

As the evidence surrounding MAG continues to develop, special concern has been turned toward specific patient populations who would benefit most from this grafting strategy, such as older individuals, female patients, and patients with important comorbid conditions like diabetes. Patients with diabetes, in particular, present

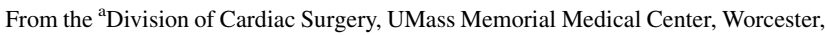
Mass; and ${ }^{\mathrm{b}}$ Department of Cardiothoracic Surgery, Weill Cornell Medicine, New York, NY.

Received for publication March 8, 2021; revisions received March 8, 2021; accepted for publication March 12, 2021; available ahead of print April 20, 2021.

Address for reprints: Mario Gaudino, MD, Department of Cardiothoracic Surgery, Weill Cornell Medicine, 525 E 68th St, New York, NY 10065 (E-mail: mfg9004@med.cornell.edu).

J Thorac Cardiovasc Surg 2021;162:103-6

$0022-5223 / \$ 36.00$

Copyright (c) 2021 by The American Association for Thoracic Surgery

https://doi.org/10.1016/j.jtcvs.2021.03.105
}

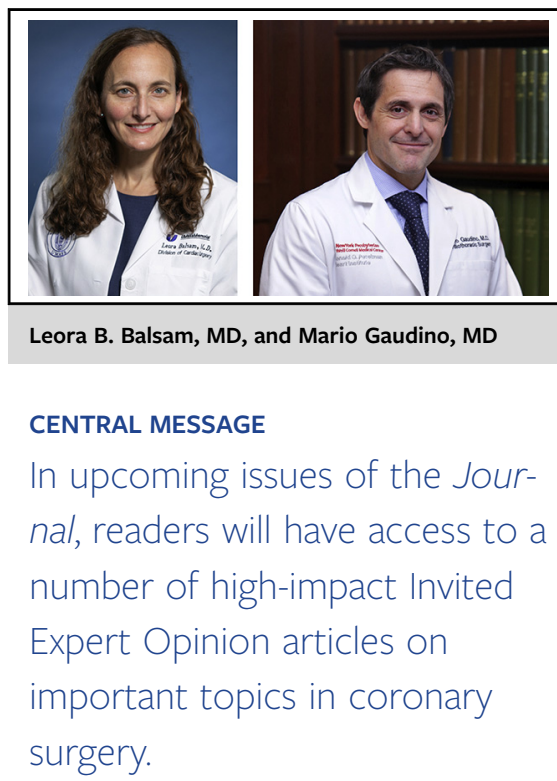

a unique challenge to coronary surgeons. In their Invited Expert Opinion article, Akhrass and Bakaeen ${ }^{8}$ will summarize the pathophysiology and anatomy of coronary disease in patients with diabetes, delve into the literature related to the most appropriate revascularization strategy, and discusses the role of MAG.

Four leaders in the field of coronary artery disease distill the recently published results of the International Study of Comparative Health Effectiveness With Medical and Invasive Approaches (ISCHEMIA) trial ${ }^{9}$ and its implications on surgical myocardial revascularization in another Invited Expert Opinion article. ${ }^{10}$ The ISCHEMIA trial, which was designed to compare an initial conservative strategy with an initial revascularization strategy for stable ischemic heart disease, found similar outcomes in both groups at a median of 3.2 years of follow-up. The authors will explain how these findings do not negate the value of CABG in stable ischemic heart disease, but rather highlight the importance of including a medical therapy expert alongside surgeons and interventionalists in heart team discussions. ${ }^{10}$

Gaudino and Brophy ${ }^{11}$ will help readers critically evaluate recent trials and meta-analyses on the management of severe left main coronary artery disease. They explain how differences in study design have led to discordant results on the merit of percutaneous coronary intervention (PCI) versus CABG, using the Evaluation of XIENCE Versus Coronary Artery Bypass Surgery for Effectiveness of Left Main Revascularization (EXCEL) and Percutaneous Coronary Angioplasty Versus Coronary Artery 
Bypass Grafting in Treatment of Unprotected Left Main Stenosis (NOBLE) trials for management of low- and medium-complexity left main coronary artery disease as examples. Based on the totality of current evidence, they conclude that surgical management should be the standard of care.

The management of chronic coronary syndromes remains unclear. Doenst and Sigusch ${ }^{12}$ will argue that CABG, compared with PCI, confers greater long-term benefits in these patients by not only revascularizing ischemic myocardium but also by preventing new infarctions through "surgical collateralization" of nonflow-limiting lesions. These are identified in more than $85 \%$ of subsequent infarctions, but are not typically addressed during PCI. ${ }^{12}$ This explanation has important implications as it relates to modern coronary surgery and the use of MAG as well as fractional flow reserve (FFR).

FFR, in fact, may have a limited role in CABG. Glineur and colleagues ${ }^{13}$ from Ottawa Heart Institute present a summary of the evidence of FFR in CABG. FFR has demonstrated clear benefit in PCI, showing superiority versus angiographic-guided revascularization. Glineur and colleagues ${ }^{13}$ review why FFR is of limited applicability in CABG, a surgical strategy aimed not only at addressing acute ischemia, but also at preventing future events. They argue that FFR has utility in determining the type of graft to use (ie, arterial vs venous). ${ }^{13}$

Graft patency remains of paramount importance. Microvesicles in the circulation may play a role in graft thrombosis. In their Invited Expert Opinion article, Moore and Harken ${ }^{14}$ will suggest that and increase in microvesicles with tissue factor expression may explain the etiology of graft thrombosis in certain patients. The authors suggest that this pathway of thrombosis may offer specific, targeted therapies to prevent graft occlusion; however, further investigation is needed before clinical implementation. ${ }^{14}$

Looking forward, Ryan and colleagues ${ }^{15}$ from Baylor College of Medicine will offer a thoughtful review of therapeutic angiogenesis and direct cellular reprogramming. The authors highlight how both can address the current gap in therapeutic options that exist for patients with no-option refractory angina and heart failure due to severe coronary artery disease. Their review offers a compelling statement on the current state of preclinical trials in this arena, with the high potential for clinical translation.

Finally, 2 reviews in JTCVS Techniques offer readers insight into intraoperative strategies related to the radial artery (RA) and graft patency. Most of the data that led to the reintroduction of the RA in coronary surgery can be attributed to James Tatoulis and colleagues from Melbourne. In an upcoming review of RA harvesting and preservation strategies, Tatoulis and colleagues ${ }^{16}$ offer a pragmatic approach to make even the most unfamiliar surgeon comfortable with using the RA in CABG. Additionally, as the use of intraoperative graft flow verification becomes more common, Akhrass and Bakaeen ${ }^{17}$ will encourage routine use with judicious interpretation to avoid unnecessary graft revision.

We are grateful to all of the authors for their important contributions and have no doubt that our readers will benefit from their expertise. These Invited Expert Opinions were solicited from widely published authors across coronary surgery and will help surgeons internationally make evidence-based, informed decisions to improve patient outcomes.

\section{Conflict of Interest Statement}

The authors reported no conflicts of interest.

The Journal policy requires editors and reviewers to disclose conflicts of interest and to decline handling or reviewing manuscripts for which they may have a conflict of interest. The editors and reviewers of this article have no conflicts of interest.

\section{References}

1. Gaudino M, Benedetto U, Fremes S, Ballman K, Biondi-Zoccai G, Sedrakyan A, et al. Association of radial artery graft vs saphenous vein graft with long-term cardiovascular outcomes among patients undergoing coronary artery bypass grafting: a systematic review and meta-analysis. JAMA. 2020; 324:179-87.

2. Buxton BF, Hayward PA, Raman J, Moten SC, Rosalion A, Gordon I, et al. Long-term results of the RAPCO trials. Circulation. 2020;142: $1330-8$.

3. Gillmore T, Rocha RV, Fremes SE. Evidence-based selection of the second and third arterial conduit. J Thorac Cardiovasc Surg Open. 2021; 5C:66-9.

4. Gaudino M, Rahouma M, Habib RH, Hameed I, Robinson NB, Farrington WJ, et al. Surgeons' coronary bypass practice patterns in the United States. J Am Coll Cardiol. 2020;76:1714-5.

5. Gaudio M, Kurlansky P, Fremes S. The use of the radial artery for coronary artery bypass grafting improves long-term outcomes: and now what? J Thorac Cardiovasc Surg. November 10, 2020 [Epub ahead of print].

6. Vallely MP, Ramponi F, Seco M, Royse A. Multiarterial grafting: why is it so hard to convince the masses of the benefits? J Thorac Cardiovasc Surg. 2020; 161:1832-6.

7. Kurlansky P. Multiarterial grafting: the answer to that question. J Thorac Cardiovasc Surg. 2020;161:1828-31.

8. Akhrass R, Bakaeen F. The advantage of surgical revascularization in diabetics with multivessel disease: more arterial conduits, more benefit. J Thorac Cardiovasc Surg. February 27, 2021 [Epub ahead of print].

9. Maron DJ, Hochman JS, Reynolds HR, Bangalore S, O'Brien SM, Boden WE, et al. Initial invasive or conservative strategy for stable coronary disease. $N$ Engl J Med. 2020;382:1395-407.

10. Ruel M, Sun LY, Farkouh ME, Gaudino MF. Implications of the ISCHEMIA trial on the practice of surgical myocardial revascularization. J Thorac Cardiovasc Surg. September 9, 2020 [Epub ahead of print].

11. Gaudino M, Brophy JM. The controversy on the treatment of left main coronary artery disease. J Thorac Cardiovasc Surg. November 10, 2020 [Epub ahead of print].

12. Doenst T, Sigusch H. Surgical collateralization: the hidden mechanism for improving prognosis in chronic coronary syndromes. J Thorac Cardiovasc Surg. November 10, 2020 [Epub ahead of print].

13. Glineur D, Chong AY, Grau J. What should be the role of fractional flow reserve measurement in patients undergoing coronary artery bypass grafting? J Thorac Cardiovasc Surg Open. 2021;5C:74-9.

14. Moore H, Harken A. Managing microvesicles or Virchow's vicissitude. J Thorac Cardiovasc Surg. November 10, 2020 [Epub ahead of print]. 
15. Ryan C, Patel V, Rosengart TK. Clinical potential of angiogenic therapy and cellular reprogramming. J Thorac Cardiovasc Surg Open. March 18, 2021 [Epub ahead of print].

16. Tatoulis J. The radial artery: an important component of multiarterial coronary surgery and considerations for its optimal harvest. J Thorac Cardiovasc Surg Tech. 2021;5:46-55.
17. Akhrass R, Bakaeen FG. Intraoperative graft patency validation: friend or foe? J Thorac Cardiovasc Surg Tech. January 05, 2021 [Epub ahead of print].

Key Words: CABG, coronary artery bypass, coronary surgery 


\section{Adult Coronary Surgery: Recent Articles from AATS Journals}
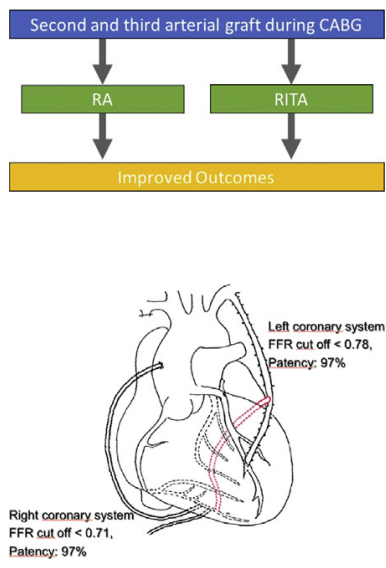

Patency: $97 \%$
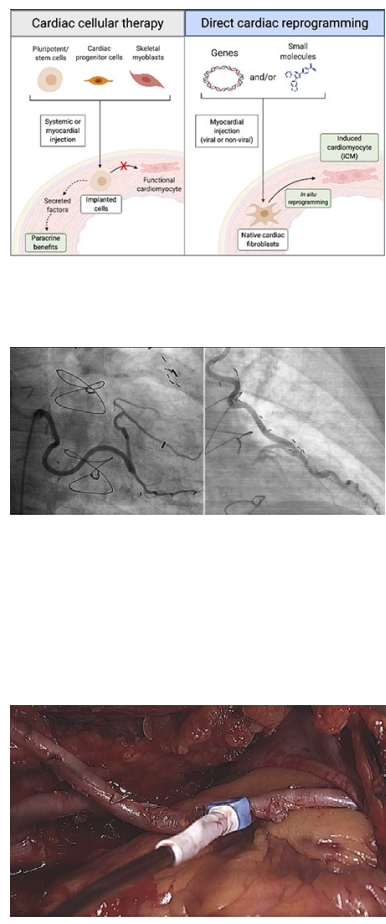

JTCVS Open: Evidence-based selection of the second and third arterial conduit. Gilmore T, Rocha RV, Fremes SE. J Thorac Cardiovasc Surg Open. 2021;5:66-69.

Commentary: One artery does not fit all: Tailoring the operation to the patient. Lawton JS. J Thorac Cardiovasc Surg Open. 2021:5:70-71.

Commentary: 1, 2 or 3 arterial grafts? One is not enough! Schwann TA, Engelman DT. J Thorac Cardiovasc Surg Open. 2021;5:72-73.

JTCVS Open: What should be the role of fractional flow reserve measurement in patients undergoing coronary artery bypass grafting? Glineur D, Chong AY, Grau J. J Thorac Cardiovasc Surg Open. 2021;5:74-79.

Commentary: Fractional flow reserve for coronary artery bypass graft surgery-Not yet ready for prime time. Lazar HL. J Thorac Cardiovasc Surg Open. 2021;5:80-82.

Commentary: Mobilizing the reserves in coronary artery bypass grafting with and without fractional flow. Doenst T, Diab M, Faerber G, Richter M. J Thorac Cardiovasc Surg Open. 2021;5: 83-84.

JTCVS Open: Clinical potential of angiogenic therapy and cellular reprogramming. Ryan CT, Patel V, Rosengart TK. J Thorac Cardiovasc Surg Open. 2021 [In press].

Commentary: Cardiac cellular "time travel" to when it was bouncing. Nishida H, Ota T. J Thorac Cardiovasc Surg Open. 2021 [In press].

Commentary: Cellular reprogramming for myocardial regeneration and beyond. Akhmerove A, Ramzy D. J Thorac Cardiovasc Surg Open. 2021 [In press].

JTCVS Techniques: The radial artery: An important component of multiarterial coronary surgery and considerations for its optimal harvest. Tatoulis J. J Thorac Cardiovasc Surg Tech. 2021;5:46-55.

Commentary: The radial won't bite, if you treat it right. Aziz H, Lawton JS. J Thorac Cardiovasc Surg Tech. 2021:5:56-57.

Commentary: Radial artery tips from Melbourne: We stand on the shoulder of giants.

Robinson NB, Gaudino M. J Thorac Cardiovasc Surg Tech. 2021:5:58-59.

Commentary: Radial artery — Try it; you might like it, and your patients will love it. Schwann TA. J Thorac Cardiovasc Surg Tech. 2021;5:60-61.

JTCVS Techniques: Intraoperative graft patency validation: Friend or foe? Ganapathi AM, Mokadam NA. J Thorac Cardiovasc Surg Tech. 2021 [In press].

Commentary: Transit time flow measurement: Similar to the National Football League's "play under review" for arterial and venous coronary artery bypass grafts. Baciewicz Jr. F. J Thorac Cardiovasc Surg. 2021 [In press].

Commentary: Intraoperative graft patency assessment: Just do it! Tam DY, Fremes SE. J Thorac Cardiovasc Surg Tech. 2021 [In press].

Commentary: Graft flow assessment-Friend, not foe, preventing vertigo and crash. Locker C. J Thorac Cardiovasc Surg Tech. 2021 [In press]. 